\title{
Os suportes de uma comunidade virtual de aprendizagem: uma experiência do Governo do Estado de São Paulo, Brasil
}

Tania Tavares-Silva, Paulo Dias e José Armando Valente

\section{Introdução}

No âmbito corporativo de uma instituição como a Escola de Governo e Administração Pública (Egap), da Fundação do Desenvolvimento Administrativo (Fundap), que se preocupa com a formação de servidores da administração pública, as questões de fundo que se colocam são:

- Como capacitar grande número de servidores e proporcionar-lhes uma aprendizagem continuada mediante cursos on-line usando métodos e técnicas de ensino que estejam de acordo com a especificidade da tarefa a ser realizada?

- Como incorporar, nos cursos baseados no paradigma da produção em massa, suportes que contribuam para que o servidor seja capaz de construir, no seu local de trabalho, as condições necessárias e propícias às mudanças profissionais e de aprendizagem? 
Nas instituições governamentais brasileiras, a implantação da Internet, além de ter ajudado a obter respostas para essas indagações, vem facilitando a aprendizagem continuada dos servidores por intermédio de capacitações on-line. Isso tem permitido implantar uma nova abordagem de educação, realizada no local de trabalho e com várias vantagens, tanto para os servidores quanto para o professor que ministra o curso (VALEnte e TAVAres-Silva, 2003).

Certamente, a evolução tecnológica tem alcançado papel relevante no processo de maturação da Educação a Distância (EaD) como uma alternativa no processo de ensino e aprendizagem de grande número de alunos, como é o caso dos servidores do Estado de São Paulo.

E é nesse contexto que as comunidades virtuais de aprendizagem (CVA) são hoje uma das ferramentas mais poderosas para discutir ideias e construir conhecimento atualizado, em que se somam as experiências de muitas pessoas. Todavia, conforme destaca Dias (2007), o objetivo de uma CVA

está para além do acesso à rede de informação, a qual, só por si, representa a entrada num ambiente enriquecido de materiais e conteúdos, e não propriamente um fator de mudança e inovação para a aprendizagem. O desenvolvimento da inovação no interior da comunidade realiza-se através da capacidade de atribuir sentido a estes materiais no âmbito do projeto da comunidade, contribuindo para esta finalidade os processos de mediação colaborativa na experiência das figurações e narrativas do conhecimento e dos contextos e práticas da sua aplicação e utilização (DIAs, 2007, p.36).
Logo, não basta somente o acesso à rede de informação, mas, sim, como essa rede poderá contribuir para desenvolver habilidades que interessam ao bom desempenho do servidor em seu trabalho, além de desenvolver habilidades que têm a ver com a possibilidade de continuar a aprender.

Assim, nossa proposta neste artigo será apresentar e discutir quais foram os suportes que ampararam as CVA da Fundap/Egap no período de 2000 a 2012 e proporcionaram, com isso, a criação de um espaço de trocas de informação, de construção do conhecimento e de aprendizagem significativa.

\section{O que é a Fundap}

A Fundap foi criada pela Lei n⿳ 435 , de 24 de junho de1974, e teve seus estatutos aprovados em 1976, data de sua efetiva instalação e do início de seus trabalhos. Atualmente vinculada à Secretaria de Gestão Pública do Estado de São Paulo, Brasil, a fundação tem personalidade jurídica de direito privado e dispõe de autonomia técnica para executar suas atividades; sua "missão institucional é garantir um permanente movimento de atualização das estruturas, procedimentos e práticas administrativas" (FARIA, 1997, p. 192).

Para tanto, a Fundap/Egap repousa sobre o seguinte tripé: ensino, desenvolvimento organizacional e pesquisa.

A Fundap possui, em sua estrutura, a Egap, que é um centro de capacitação de executivos do setor público para o exercício da gestão pública, com vistas ao aperfeiçoamento de profissionais capazes de formular diretrizes e políticas governamentais, de implementar e gerenciar políticas, e de gerar e prestar bons serviços públicos à sociedade. 
A metodologia educacional adotada na capacitação enfatiza a prática profissional, à luz de conceitos e ferramentas que ajudem a definir e superar os problemas que afetam o desempenho do serviço público. Nesse sentido, a Fundap procura manter estreita articulação com instituições e profissionais especializados que estejam produzindo conhecimento e tecnologia de interesse ao setor público. A própria estrutura da Fundap favorece essa concepção, já que a instituição opera como uma "ponte" entre a administração pública e as instituições universitárias. Seu Conselho de Curadores - instância máxima de direção - é composto de representantes da Fundação Getúlio Vargas (FGV), da Universidade de São Paulo (USP), da Universidade Estadual de Campinas (Unicamp) e da Universidade Estadual Paulista (Unesp).

Até o ano de 2000, a Fundap/Egap vinha realizando cursos de capacitação basicamente mediante ações presenciais, atendendo a uma pequena demanda de participantes por curso. A partir dessa data, pensando nos aspectos extremamente importantes para o desenvolvimento de processos educacionais com qualidade e considerando que a tecnologia computacional está cada vez mais presente nos postos de trabalho dos servidores públicos, a Fundap/Egap iniciou estudos e ações voltados à aplicação dos recursos das tecnologias de informação e comunicação (TIC) na educação.

$\mathrm{O}$ objetivo tem sido incorporar de forma sistemática e permanente as TIC nas atividades educacionais, principalmente na $\mathrm{EaD}$ via Internet, com a finalidade de tornar o participante um sujeito mais ativo no processo de aprendizagem e de recolocar a comunicação interpessoal no centro dos métodos da educação, utilizando, para isso, diferentes abordagens de $\mathrm{EaD}$.

\section{O que é uma comunidade virtual de aprendizagem}

Para Dias (2007), o surgimento de uma CVA acontece a partir da definição negociada dos objetivos da aprendizagem, da mediação colaborativa e do suporte do grupo para as reestruturações das figurações do conhecimento.

Ainda conforme esse autor, o desafio proposto pelas comunidades de aprendi-

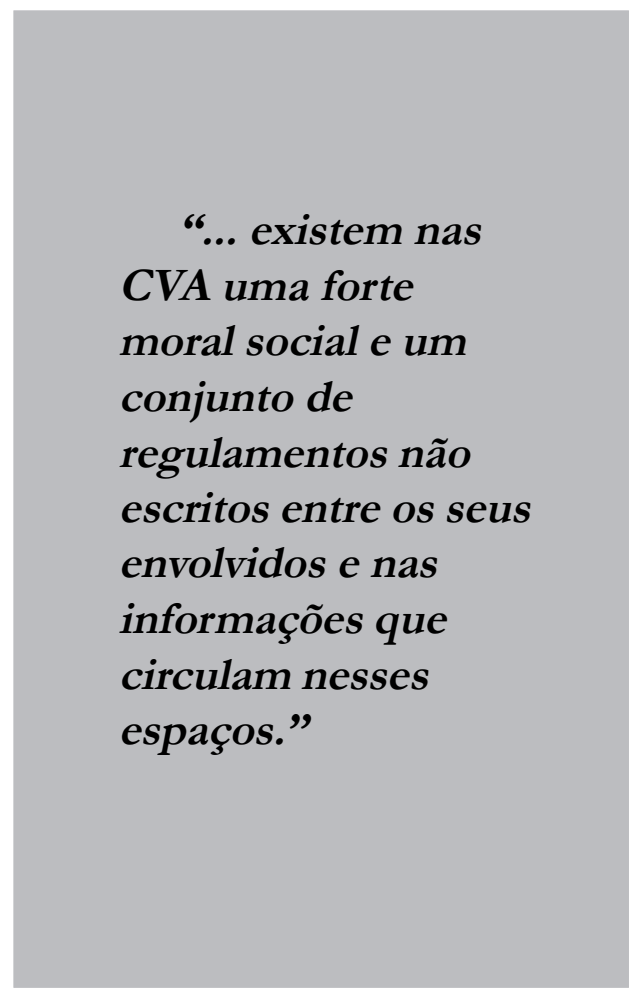

zagem "consiste na criação de uma pedagogia baseada na partilha, na exposição das perspectivas individuais entre os pares e na iniciativa conjunta orientada para a inovação e a criação" (DiAs, 2007, p. 35).

Para Lévy (2000), Palloff e Pratt (2002), a gênese de uma CVA baseia-se na afinidade de interesses, de conhecimentos, de projetos mútuos e de valores estabelecidos 
por meio de um processo de colaboração. Assim, as CVA são hoje uma das ferramentas mais poderosas para discutir ideias e construir conhecimento, uma vez que se somam as experiências de muitas pessoas. Conforme destaca Palloff e Pratt (2002, p. 47), uma comunidade de aprendizagem estabelece-se quando "unem-se pessoas que possuem interesses e objetivos similares, ou seja, pessoas que não estão conectadas por acaso, como se verifica em outras áreas do ciberespaço".

Ademais, verificamos, mediante nossa prática, que a palavra comunidade apresenta uma diversidade de sentidos e conotações emotivas. Percebemos que o que une os participantes em uma comunidade não é sua estrutura, mas o estado de espírito e o sentimento de pertencimento dos indivíduos dessas comunidades.

No diálogo com Lévy (2000), observase que as comunidades de aprendizagem constituem-se nas relações interpessoais impregnadas de emoções, não distantes e frias. Em concordância com Lévy (2000), Tavares-Silva (2003) enfatiza que, nessas comunidades, o importante é resgatar a funcionalidade da emoção ${ }^{1}$ como condição capaz de proporcionar circunstâncias adequadas aos anseios e desejos dos participantes, tornando esses ambientes adaptáveis aos seus integrantes e possibilitando uma boa interface de comunicação e interação.

Silva (1998, p. 95), por sua vez, complementa esse argumento, ao afirmar que a CVA é um "espaço de construção (um território simbólico) marcado pela extensão e pela profundidade da interação entre os indivíduos de construir esse todo".

Com isso, existem nas CVA uma forte moral social e um conjunto de regulamentos não escritos entre os seus envolvidos e nas informações que circulam nesses espaços.
De acordo com Palloff e Pratt (2002), as relações e os limites individuais e coletivos estão ancorados em algumas regras preestabelecidas e amplamente divulgadas, dentre as quais se destacam: honestidade, correspondência, pertinência, respeito, franqueza e autonomia.

Nessas comunidades, há um sistema de valores e um código de moral que proporcionam aos seus membros um senso de identidade e de pertencimento.

Percebemos também, com o olhar em nossa prática, que uma CVA só sobrevive se houver um foco - afinidades de interesses -, se houver participantes responsáveis, unidos espontaneamente, compromissados, que queiram aprender, envolvidos com a colaboração (participação) e que objetivam um empreendimento coletivo. Nesse espaço, não existem hierarquias, e a gestão do conhecimento deve ser uma preocupação constante. Os participantes dessa comunidade possuem identidade na prática (reciprocidade na colaboração e no trabalho contínuo).

Todavia, os participantes, quando adultos, aprendem quando o assunto, o foco, possui um valor imediato, uma utilidade para enfrentar problemas reais de sua vida pessoal e profissional. Esse foco cria circunstâncias para o envolvimento, a presença, dos participantes e a visibilidade, pois eles sabem que as informações estão disponíveis no ambiente a qualquer momento.

Verificamos também, pela nossa prática, que os participantes passam a ser "donos" zelosos desses espaços e fazem de tudo para que a chama das interações não arrefeça e, com isso, possam utilizar esse ambiente ao longo dos anos (continuidade), ou seja, os membros dessas comunidades têm compromisso de longo prazo com o seu desenvolvimento (criação de valores).

Os participantes entendem que uma comunidade de aprendizagem é uma 
poderosa ferramenta de trabalho, pois podem resolver os problemas do seu dia a dia de trabalho por meio da contribuição, de experiências dos colegas (diversidade de talentos dos seus membros). Também o interagir com os pares cria uma relação de confiança, amizade e bem-estar (pertencimento).

Todavia, enfatizamos, com base em nossa prática, que a espontaneidade pode não ser o meio eficiente para gerar conbecimento. Nesse caso, é imprescindível a presença dos mediadores técnicos e dos mediadores pedagógicos. O mediador deve ser um facilitador da aprendizagem; deve estabelecer relações dialógicas e de parceria com os aprendizes; deve procurar valorizar a bagagem de conhecimento trazida por seus aprendizes. Os mediadores criam circunstâncias para trabalhar melhor a informação e isso gera melhor qualidade de conhecimento. Não conseguimos vislumbrar uma comunidade sem esses intervenientes, pois, caso contrário, o "barco" pode afundar!

Além disso, as CVA da Fundap/Egap possuem diferentes niveis de participação. Também verificamos que há, como Wenger (1998) acena, três tipos grupais:

- um grupo nuclear (pequeno grupo que tem como tônica a paixão pelo que faz e, consequentemente, possui grande envolvimento);

- um grupo com adesão completa (grupo que é reconhecido pela comunidade, em virtude de suas contribuições e envolvimentos, e que define o andar da comunidade);

- um grupo com participação periférica (grupo que pertence à comunidade, mas que tem menor envolvimento; em algumas vezes, seus membros são novatos ou, então, não têm envolvimento com a prática).

Dessa forma, a sociedade do conhecimento e a emergência de uma nova economia "informacional" e globalizada demandam capital intelectual (CASTELLS, 1996), pessoas com competência para participar ativamente, saber trabalhar em grupo, pensar e criar soluções para problemas complexos, e aprender continuamente. Essa nova mentalidade deve permear todos os cidadãos, produtores ou consumidores de todos os segmentos sociais, incluindo o setor público.

Assim, é importante analisar as possibilidades de aplicar o conceito de comunidades de prática no contexto dos setores público, privado e terceiro setor, uma vez que elas se constituem em uma ferramenta aglutinadora de ações individuais e organizacionais.

\section{O desafio: como capacitar três mil servidores em um curso na abordagem broadcast e criar circunstâncias para a construção do conhecimento via CVA}

Como já afirmado, até o ano de 2000 a Fundap/Egap vinha realizando cursos de capacitação basicamente mediante ações presenciais, atendendo a uma pequena demanda de participantes por curso.

A partir dessa data, pensando nos aspectos extremamente importantes para o desenvolvimento de processos educacionais com qualidade, na educação continuada, e considerando que a tecnologia computacional está cada vez mais presente nos postos de trabalho dos servidores públicos, a Fundap/Egap iniciou estudos e ações voltados à aplicação dos recursos das TIC na educação. O objetivo tem sido incorporar sistemática e permanentemente as TIC nas atividades educacionais, principalmente na EaD via Internet, a fim de tornar o participante um sujeito mais ativo no processo de aprendizagem e de recolocar a comunicação interpessoal no 
centro dos métodos da educação, usando, para isso, diferentes abordagens de EaD.

Os primeiros cursos de $\mathrm{EaD}$ ofertados pela Fundap/Egap foram baseados na abordagem do estar junto virtual e no uso da plataforma TelEduc (Rocha, 2002). O estar junto virtual (VALENTE, 2009) prevê alto grau de interação entre professor e aprendizes, e entre os próprios aprendizes. A Internet proporciona os meios para que essas interações sejam intensas, permitindo o acompanhamento do aluno e a criação de condições para o professor "estar junto", ao lado do aluno, vivenciando e auxiliando-o a resolver seus problemas, porém virtualmente.

O TelEduc é um ambiente de suporte a atividades de ensino e aprendizagem via Internet, desenvolvido no Núcleo de Informática Aplicada à Educação (Nied) e no Instituto de Computação da Universidade Estadual de Campinas (Unicamp), São Paulo.

Cada curso ofertado pela Fundap/ Egap, que utilizava o ambiente TelEduc na abordagem estar junto virtual, envolvia cerca de trinta participantes. Em 2002, a Fundap/Egap foi consultada pela Secretaria de Gestão Pública do Estado de São Paulo para realizar o Curso de Licitação e Gestão de Contratos, mediado por computador, via Internet, para cerca de três mil servidores do Estado.

Dada essa demanda, surgiu o grande desafio: como sair de cursos para trinta alunos e partir para cursos com mais de três mil participantes, mas sem desperdiçar o potencial do aprendiz de interagir, pensar e criar?

Esse desafio levou a uma série de questões tendo em vista a experiência com as atividades de EaD da Fundap/Egap, que primavam pela intensidade e qualidade da interação e, consequentemente, pelo processo de construção de conhecimento.
Uma das questões, por exemplo, era como incorporar, nos cursos a distância destinados a um grande número de participantes, aspectos pedagógicos que contribuíssem para que o servidor fosse capaz de construir, no seu local de trabalho, as condições necessárias e propícias às mudanças profissionais e de aprendizagem?

A solução ${ }^{2}$ foi a criação de uma CVA amparada pelos seguintes suportes:

- criação de um curso na abordagem broadcast ${ }^{3}$;

- mediação pedagógica e técnica, à luz do estar junto virtual;

- efetiva contribuição dos participantes;

- aprendizagem continuada e colaborativa.

Para atender a esse primeiro desafio, a equipe de EaD da Fundap/Egap, como ainda não dispunha, em 2002, de uma ferramenta de EaD para atender a um grande número de participantes, recorreu à criatividade e passou a utilizar uma ferramenta estática ${ }^{4}$, desenvolvida em páginas HTML para abrigar o conteúdo programático de seus cursos.

Ao iniciarmos a construção da ferramenta estática $\left(\right.$ tutorial $^{5}$ ), tínhamos a seguinte preocupação: o modelo educacional homogêneo não é vivenciado por todos os aprendizes da mesma maneira (os aprendizes diferem quando aprendem!).

Assim, a construção dessa ferramenta estática procurou contemplar as diversas preferências de aprendizagem dos participantes, uma vez que alguns participantes aprendem com textos e gráficos; outros, com imagens, filmes, análises de casos; outros ainda, interagindo com os seus pares em um ambiente de diálogo (comunidade) etc. (CAVEllucci, s.d.). Percebemos que uma única forma de apresentar o conteúdo do curso (por exemplo, somente uma apostila) não atingiria a todos os participantes 
de igual maneira. A ferramenta possibilitou, pois, contemplar diferentes dinâmicas de apresentação do conteúdo dos módulos e, assim, atingir cada um dos estilos de aprendizagem.

As Figuras 1 e 2 mostram o cuidado em contemplar diferentes formas de apresentar o conteúdo do curso (texto, figura, pop-up ${ }^{6}$, sites etc.).

O tutorial compõe-se de sete módulos ${ }^{7}$. Cada módulo organiza-se nos seguintes subcampos: conteúdo, tema, exercícios, apontamentos, pesquisa e saiba mais. Além disso, o curso conta com recursos extras: ajuda, midiateca, glossário, créditos e questões interessantes ${ }^{8}$.

Embora sequencial, o participante pode seguir essa ordem ou qualquer outra que lhe parece mais conveniente (não há bloqueio de módulos que obrigue o participante a obedecer a sequência linear de apresentação dos módulos do curso). Entretanto, em todos os módulos, os assuntos estão relacionados e indicados por meio de links, permitindo que o participante retorne, quando necessário, aos conceitos apresentados nos demais módulos. Todos os módulos possuem a mesma estrutura, o que facilita a navegação do participante nos demais módulos depois de ter navegado em um módulo, conforme indicado na Figura 3.

Como não existe bloqueio de módulos, o participante é o responsável por seu aprendizado e pode escolher por onde começar, quando, o que e como estudar.

Conforme mostra a Figura 3, cada módulo contém doze exercícios (exceção para o Módulo 4, que conta com quatorze exercícios). Esse curso disponibiliza 74 exercícios em formatos diferentes (animações, completar o texto, palavras cruzadas, arrastar palavras, ouvir uma música ou assistir a um filme etc.). Todas as alternativas dos exercícios são comentadas, possibilitando que o participante aprenda com o seu erro. A Figura 4 mostra esse recurso.

Todavia, o objetivo da Fundap/Egap era transformar a metodologia bem-sucedida do ambiente estático em um ambiente LMS dinâmico, com um design mais limpo, porém mantendo toda a facilidade de navegação até então adotada e aprovada pelos alunos (o segundo desafio encontrado).

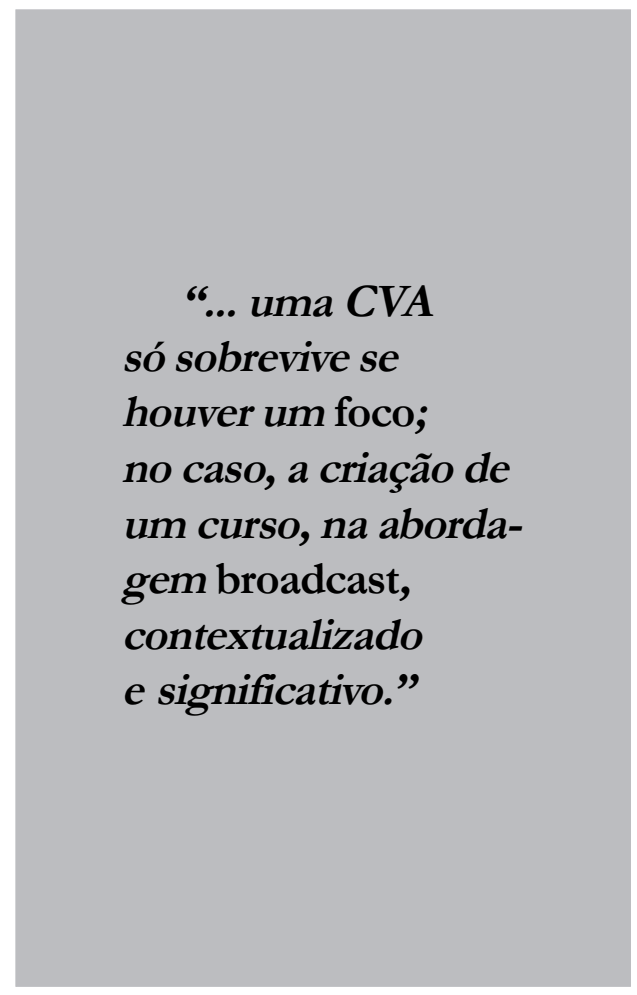

Além da criação do tutorial (conteúdo do curso), a Fundap/Egap customizou um software livre - Snitz (http://forum. snitz.com) -, que compreendeu a tradução do ambiente para o português, uma nova configuração de cores e a seleção e adaptação de alguns dos recursos oferecidos pelo software; com isso, criou o espaço de interação (a CVA). 


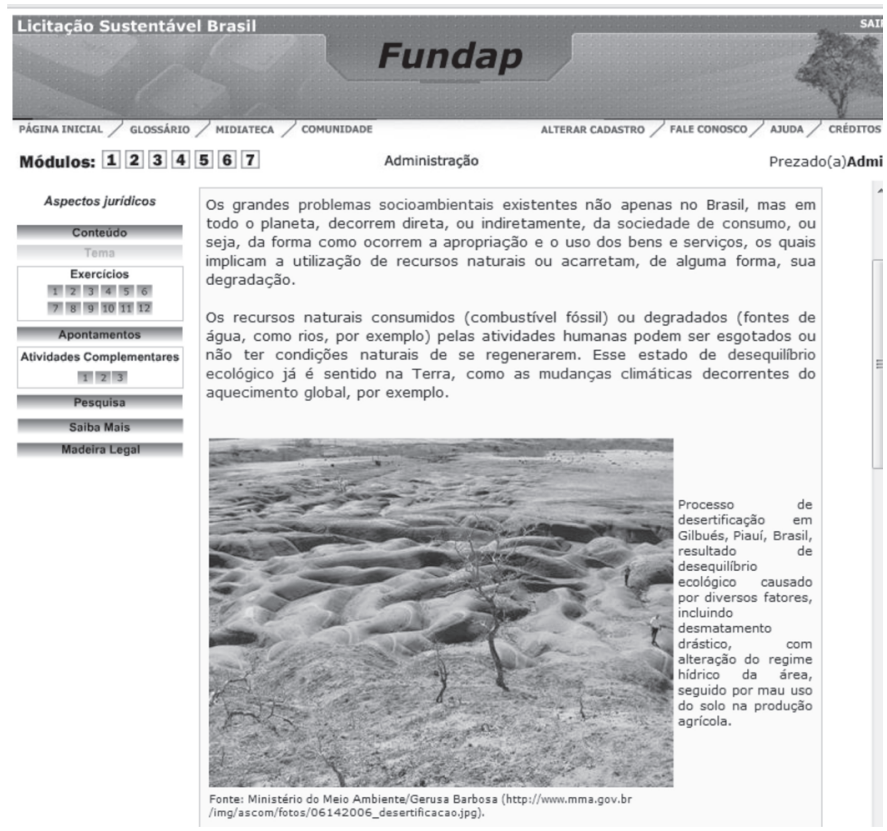

Fonte: Curso de Licitação Sustentável Brasil, Fundap (2012)

Figura 1: Diferentes formas de apresentar o conteúdo: texto e figuras

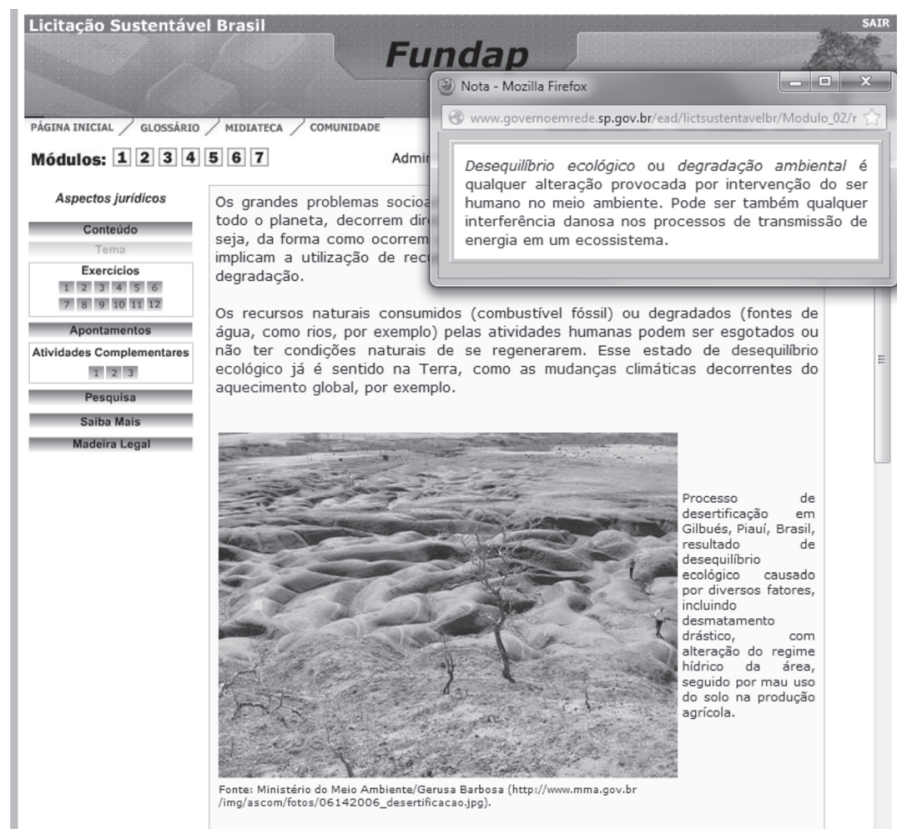

Fonte: Curso de Licitação Sustentável Brasil, Fundap (2012)

Figura 2: Diferentes formas de apresentar o conteúdo: pop-up 


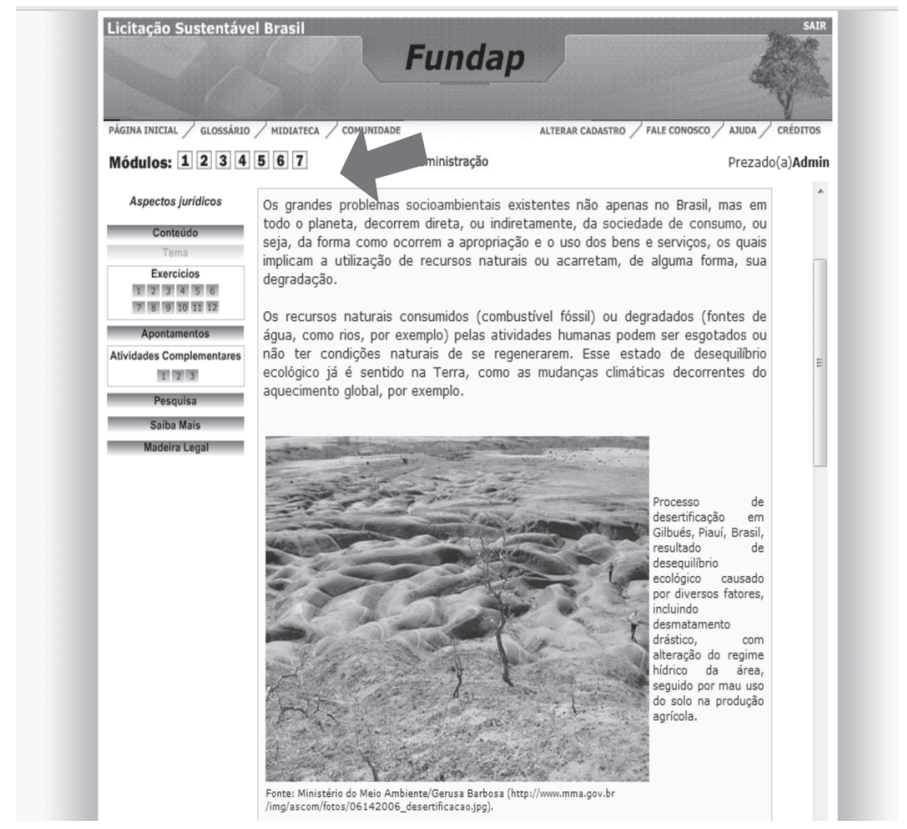

Fonte: Curso de Licitação Sustentável Brasil, Fundap (2012)

\section{Figura 3: Estrutura dos módulos do curso}

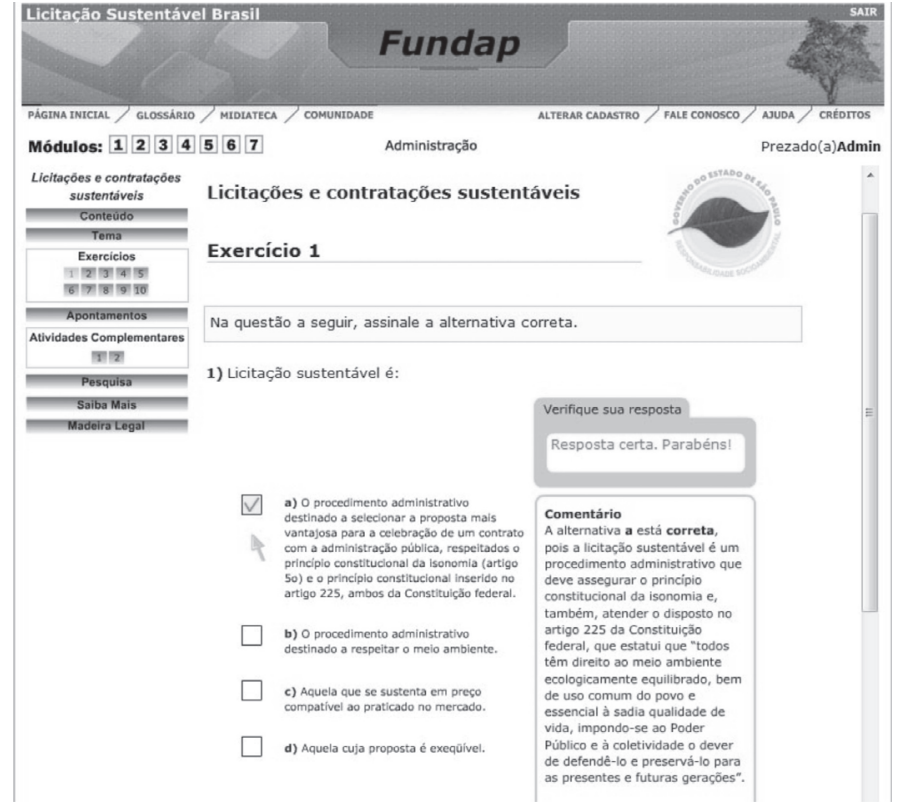

Fonte: Curso de Licitação Sustentável Brasil, Fundap (2012)

Figura 4: Diferentes formas de apresentar o conteúdo: exercícios 
A seguir, veremos em detalhes os suportes da CVA - do Curso de Licitação Sustentável Brasil -, ofertados pela Fundap/Egap em 2012.

\section{O primeiro suporte da CVA: curso na abordagem broadcast (foco)}

Verificamos, com o olhar em nossa prática, que uma CVA só sobrevive se houver um foco; no caso, a criação de um curso, na abordagem broadcast, contextualizado e significativo, uma vez que os participantes (alunos), quando adultos, aprendem se o assunto, o foco, possui um valor imediato, uma utilidade para enfrentar problemas reais de sua vida pessoal e profissional.

Esse foco cria circunstâncias para o envolvimento, a presença, dos participantes e a visibilidade, pois eles sabem que as informações estão disponíveis no ambiente a qualquer momento.

A abordagem broadcast não permite nenhum tipo de interação com o aluno, mas pode atingir grande número de aprendizes. O modelo preocupa-se em como a informação é armazenada, representada e, principalmente, transmitida. O computador torna-se, assim, poderosa ferramenta para armazenar, representar e transmitir a informação. Essa abordagem baseia-se no modelo tutorial, em que a informação é organizada de acordo com uma sequência pedagógica particular', sendo apresentada ao participante segundo essa sequência.

Assim, o conteúdo é preparado e organizado previamente, para só depois de pronto ser oferecido ao aprendiz, que não pode fazer nenhuma alteração. A interação do participante com o computador ocorre por meio da leitura da tela ou mediante uma teleconferência.
Esse modelo não nos fornece nenhuma pista sobre o processamento da informação, isto é, ele não permite certificarnos de que o aluno está processando a informação transmitida, nem diagnosticar como a aprendizagem está sendo processada.

O grande desafio na concepção de cursos ou programas de capacitação, nessa abordagem, é o tratamento dado ao conteúdo programático. Deve existir a preocupação com a linguagem extremamente didática e sedutora para o participante. A ênfase é mesclar teoria e prática em total sinergia com o fazer diário do participante.

Para Valente (2009), a limitação da abordagem broadcast é a ausência de interação entre mediador e aprendiz. Como o mediador não interage com o aluno, ele não recebe nenhum retorno do aprendiz e, portanto, não tem ideia de como essa informação está sendo compreendida ou assimilada. Nesse caso, o aluno pode estar ou atribuindo significado e processando a informação, ou simplesmente memorizando-a. O professor não dispõe de meios para verificar o que o aprendiz faz.

A Figura 5, a seguir, ilustra a abordagem broadcast utilizando a Internet.

A abordagem broadcast é bastante eficiente para disseminar informação a uma gama muito grande de alunos. No entanto, essa proposta não garante que o aluno esteja construindo conhecimento.

A interação do participante ${ }^{10} \mathrm{com} \mathrm{o}$ conteúdo consiste em ler a tela do curso no computador, responder a perguntas, buscar informação em diferentes materiais de apoio, ou mesmo fazer o download de um documento que contenha todo o conteúdo tratado em um módulo. Essa abordagem não fornece pistas sobre o processamento da informação, isto é, ela não permite certificar-nos de que o 


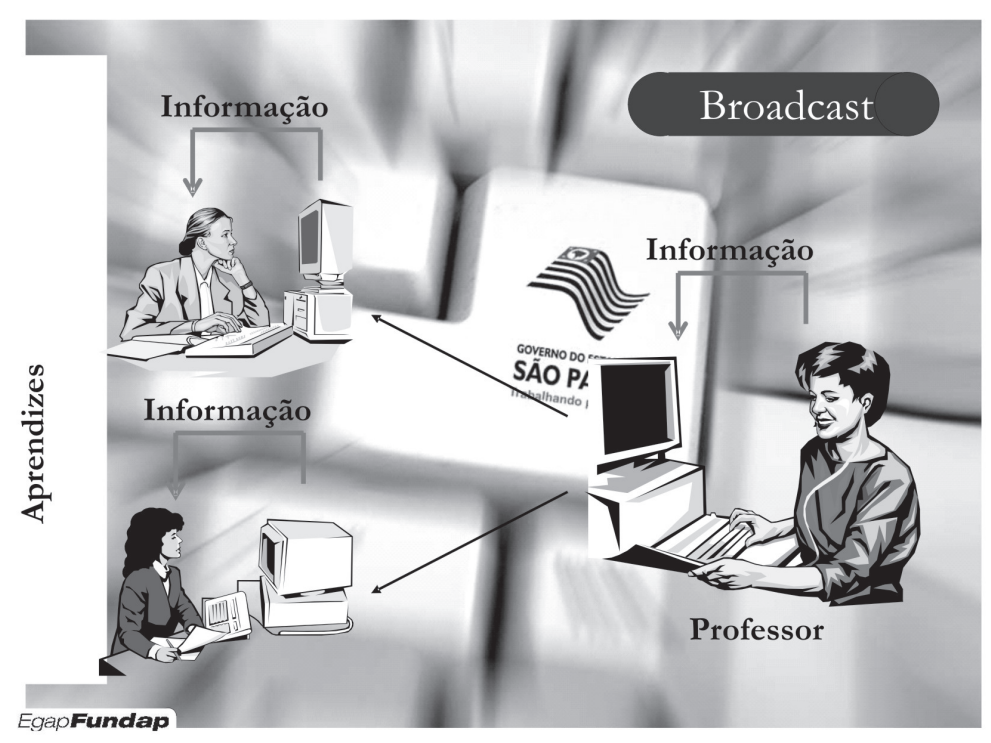

Fonte: Fundap/Egap (São Paulo, Brasil)

\section{Figura 5: Abordagem broadcast de EaD, utilizando a Internet}

aluno está processando a informação recebida, nem diagnosticar como a aprendizagem está ocorrendo.

Para contornar essas limitações, a solução encontrada pela Fundap/Egap foi desenvolver uma ferramenta na abordagem broadcast porém com diferenciais na preparação do material didático (abordagem broadcast) e com a introdução da CVA à luz do construcionismo contextualizado $^{11}$ e do estar junto virtual ${ }^{12}$ (VAlente, 2009).

Assim, vale ressaltar que a abordagem broadcast adotada pela Fundap/Egap não pressupõe um conteúdo fechado, já que o curso tem as informações atualizadas sistematicamente, pois a comunidade realimenta o tutorial, num processo contínuo, que retorna para a comunidade, favorecendo, também, a gestão do conhecimento em governo.
Os únicos pré-requisitos mínimos indispensáveis, para o servidor, são: saber navegar na Internet; usar regularmente o correio eletrônico; ter prática com editor de textos; e saber baixar arquivos (fazer download). Além disso, quanto à infraestrutura computacional, o participante deve ter acesso regular diário à Internet, com conexão estável, e o equipamento a ser utilizado deve dispor de um navegador e um programa de correio eletrônico instalados.

A Figura 6 ilustra a segunda página de abertura do Curso de Licitação Sustentável Brasil, mediado por computador e via Internet, ofertado pela Fundap/Egap em $2012^{13}$.

O grande desafio na montagem do curso - na abordagem broadcast - foi o tratamento dado ao conteúdo programático, com uma linguagem extremamente didática e sedutora para o participante; o curso 
mescla teoria e prática em total sinergia com o fazer diário do servidor, a fim de promover o processo de ensino e aprendizagem, e manter a motivação dos participantes.

Para isso, houve o cuidado em contemplar as várias preferências de aprendizagem no conteúdo programático do curso (imagens, textos, desenhos, gráficos, casos práticos, exercícios, pesquisa, filmes, interação etc.).

Conforme mostra a Figura 7, a seguir, o curso contém uma estrutura modular (sequência pedagógica particular), com a finalidade de poder atender a uma clientela bastante heterogênea, desde os servidores que começam a trabalhar em determinada área (conforme o foco de cada curso), até os que precisam ou queiram atualizar-se.

O curso não oferece, portanto, como faz a maioria dos cursos tradicionais, "primeiramente" a apostila ${ }^{14,}$ com cerca de vinte a trinta páginas por módulo, uma vez que sabemos que cada participante traz um referencial teórico e prático. Assim, entendemos que o participante traz algo para o curso e, com isso, ele poderá desejar explorar os módulos conforme a sua necessidade.

Não existe bloqueio dos módulos do curso. Dessa forma, o participante pode optar ou pela sequência pedagógica sugerida pelo curso, ou qualquer outra que lhe pareça mais interessante.

O participante é responsável por seu aprendizado e pode escolher por onde e quando começar, o que estudar e a maneira em que prefere fazê-lo.

O material de apoio do curso é organizado em uma sequência de módulos, planejada por critérios pedagógicos; cada módulo está organizado nos seguintes subcampos:

- Conteúdo, que apresenta os assuntos do módulo, o número de exercícios

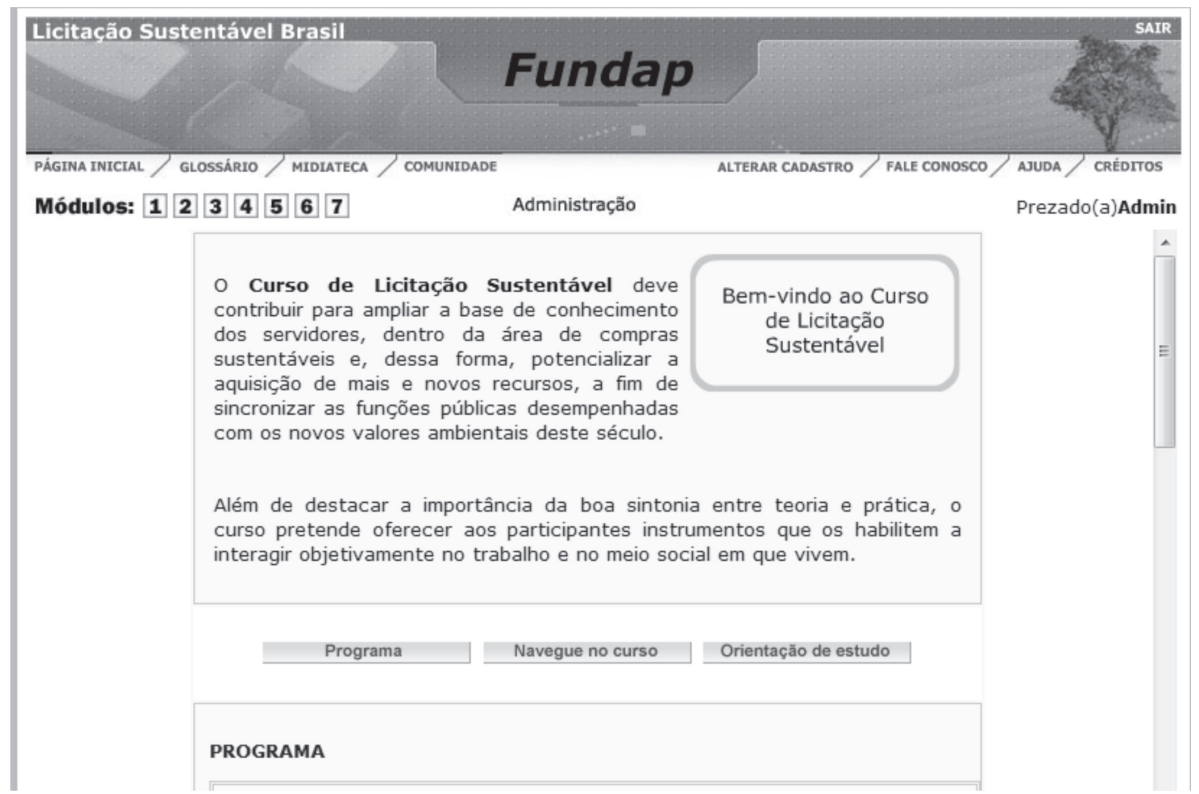

Fonte: Curso de Licitação Sustentável Brasil, Fundap (2012)

Figura 6: Segunda página de abertura do curso 
propostos, o número de casos práticos e o número de páginas da apostila (saiba mais). Informa também a autoria do módulo.

- Tema, o qual traz uma síntese dos assuntos trabalhados no módulo.

- Exercícios, propostos para que o participante do curso aplique e retenha novos conteúdos/informações.

- Apontamentos, subcampo que fornece, em tópicos curtos, os principais conceitos tratados em cada módulo do curso. Os apontamentos são os assuntos relevantes do módulo. Esse item possui, no máximo, duas rolagens de página. Representa aquilo que o participante não pode esquecer, ou seja, o participante não pode sair do módulo sem saber os conteúdos abordados nos apontamentos.

- Atividades Complementares, as quais apresentam exemplos teóricos ou práticos sobre o conteúdo programático do curso.
- Pesquisa, subcampo que indica referência bibliográfica sobre determinado módulo e apresenta sugestões de endereços interessantes a visitar, na Internet. A pesquisa ajuda o participante a fazer um aprofundamento do conteúdo do módulo, caso ele tenha interesse durante ou após o curso.

- Saiba Mais, que traz uma apostila em formato PDF, contemplando todas as informações do módulo.

O curso oferece também espaços de apoio, como comunidade, fale conosco, glossário, midiateca, questões interessantes, ajuda e créditos, conforme ilustrado na Figura 7.

O Fale Conosco permite ao participante obter informação sobre a parte administrativa do curso (informa quando o participante poderá acessar o curso, resolve problemas de navegação e dúvidas sobre a certificação). No Fale Conosco, o participante

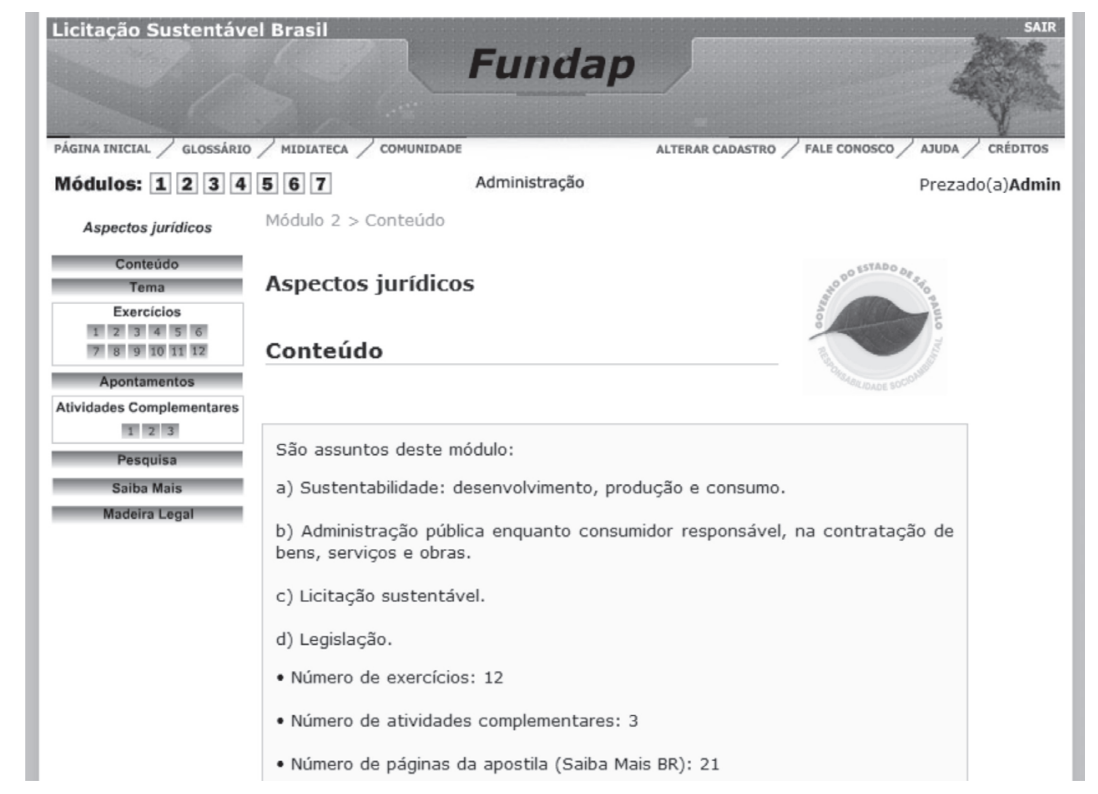

Fonte: Curso de Licitação Sustentável Brasil, Fundap (2012)

Figura 7: Estrutura dos módulos do curso 
não pode tirar dúvidas sobre o conteúdo programático do curso.

O Glossário contém os principais termos empregados em todos os módulos do curso, com definições compiladas ou elaboradas por especialistas.

A Midiateca é uma biblioteca virtual. Contém material de leitura complementar indicado por mediadores e participantes.

Questões Interessantes são questões colhidas pelo mediador técnico responsável pela comunidade, com base na interação dos participantes nos fóruns da CVA. Essas questões são colhidas após o fechamento de cada fórum (gestão da informação).

O subcampo Créditos, por sua vez, apresenta a equipe multidisciplinar do ambiente de capacitação (autores e mediadores).

No início de cada mês, uma nova turma acessava o ambiente de aprendizagem (curso e comunidade). Cada turma, com no máximo trezentos participantes, podia realizar o curso durante, no máximo, três meses. Entretanto, após o encerramento do curso, os participantes manifestavam interesse de continuar a ter acesso à CVA, como em outras comunidades ofertadas pela Fundap/Egap.

Comprovamos, pois, que o suporte da "aprendizagem continuada" é fundamental em uma CVA. A ideia é tornar esse espaço disponível aos servidores em seu dia a dia de trabalho, como um meio de aprimorar seus conhecimentos técnicos e seu desempenho profissional.

\section{O segundo suporte da CVA: mediação técnica e pedagógica, à luz do estar junto virtual}

Existe significativa diferença entre mediação técnica e mediação pedagógica, conforme postula Tavares-Silva (2006).
Os mediadores técnicos ${ }^{15}$ são conhecedores do conteúdo programático do curso, contudo, para além disso enfatizam o surgimento de novas relações em detrimento da clássica relação mediador-aluno. A intervenção do mediador técnico deve ir ao encontro da proposta que procura romper e superar o paradigma da contradição mediador-aluno (modelo conducionista).

Nesse espaço, todos - aprendizes e mediadores técnicos - detêm conhecimentos específicos, diferenciados e relevantes. Todos são coautores e coprodutores do seu próprio conhecimento e, também, ambos são coautores e coprodutores do que está sendo produzido e incorporado ao ambiente, em um movimento contínuo e recursivo. Assim, o mediador técnico é o organizador da troca de ideias, em vez de detentor do conhecimento ou de instrutor, e os aprendizes passam a ter um papel mais ativo ao explicitar seus conhecimentos e ao revelar seus talentos. O mediador técnico é diferenciado por ser a pessoa portadora de uma intencionalidade pedagógica, a qual deve preservar os objetivos originais do curso (o barco tem um timoneiro!).

Os mediadores pedagógicos não são "conhecedores" do conteúdo programático, mas têm a função de facilitar a ambientação dos alunos no curso (apresentam os fóruns de discussão, incentivam a interação nesses fóruns, auxiliam os alunos para que postem contribuições conforme o conteúdo proposto em cada fórum etc.), ou seja, os mediadores pedagógicos auxiliam o mediador técnico a conduzir os espaços de discussão.

Ainda conforme Tavares-Silva (2006), os mediadores pedagógicos, além de auxiliarem o mediador técnico a conduzir os espaços de discussão, têm o papel de resgatar a funcionalidade da emoção como 
condição capaz de proporcionar circunstâncias adequadas aos anseios dos participantes, tornando esse ambiente adaptável ao aluno e possibilitando uma boa interface de comunicação e interação; porém, sem nunca perder o foco do curso, o controle, o gerenciamento e a animação geral do ambiente de aprendizagem.

Vale enfatizar que as atuações dos mediadores - pedagógicos e técnicos estão amparadas na abordagem do estar junto virtual ${ }^{16}$, na qual o aprendiz é estimulado a desenvolver uma atuação responsável e autônoma, sendo pedagogicamente apoiado e orientado pelos mediadores dentro dos propósitos estabelecidos, pois não se objetiva ter um aluno autodidata, que não conta com uma proposta pedagógica e didática para o estudo, como alerta Litwin (2001).

Destaca-se, na abordagem estar junto virtual, a atuação dos mediadores; no entanto, acima de tudo, deve-se dar atenção especial ao fundamental papel dos aprendizes, para os quais:

A mediação pedagógica enfrenta o desafio de criar situações que propiciem a presença virtual por meio de acompanhamentos, interações e orientações que aproximam professores e alunos, fazendo com que os alunos assumam o papel de mediadores dos próprios colegas e desenvolvendo a autoaprendizagem e a aprendizagem dos seus pares. (Berehens, apud Moran, 2000, p. 82)

Para Dias (2007, p. 35), o desafio nessa abordagem é a "criação de uma pedagogia baseada na partilha, na exposição das perspectivas individuais entre os pares e na iniciativa conjunta orientada para a inovação e criação".
Nesse sentido, o estarjunto virtualé a abordagem que oferece maiores condições para implantar situações de construção de conhecimento, mas ela exige o envolvimento, o acompanhamento e o assessoramento constantes do participante por parte da mediação técnica e da mediação pedagógica.

A Figura 8, a seguir, ilustra a abordagem do estar junto virtual a partir da abordagem do construcionismo contextualizado ${ }^{17}$ utilizando a Internet.

Essa é, sem dúvida, a abordagem de maior custo, pois pressupõe acompanhamento permanente dos aprendizes por meio da mediação, pedagógica e técnica.

Portanto, a abordagem estarjunto virtual não representa o paradigma conducionista, tutorial, mas enfatiza as interações do mediador com os aprendizes, priorizando sempre as condições para a construção de conhecimento.

\section{O terceiro suporte da CVA: participantes (alunos) responsáveis e envolvidos}

Os participantes (alunos) são responsáveis pelo surgimento de um novo tipo de relação, muito diferente da clássica relação professor-aluno. Essa nova relação representa uma outra forma de comunicação e enfatiza a interação participante-participante. Os participantes devem entender que os mediadores serão facilitadores do processo de ensino e aprendizagem e não "entregadores" da informação. Eles devem estar cientes de que o mote da comunidade é a interação participante-participante.

$\mathrm{Na}$ comunidade, há uma divisão de responsabilidade, bem como posição de igualdade entre mediadores e participantes. O participante deve modificar sua atitude para vir a ser um agente de busca e construção do conhecimento, tornando-se 
coautor de seu aprendizado pessoal e profissional, uma vez que dá a sua opinião a cada questão apresentada. Cada participante é responsável pela construção do conhecimento de forma autônoma e de acordo com sua disponibilidade e ritmo pessoal. O importante é despertar em todos - participantes e mediadores - a corresponsabilidade pelo processo de construção do conhecimento.

\section{O quarto suporte da CVA: aprendizagem continuada}

Conforme já afirmado, mesmo após o encerramento do curso, os participantes manifestavam interesse em ter acesso à comunidade de aprendizagem do curso.
A ideia é tornar esse espaço disponível aos servidores em seu dia a dia de trabalho, como um meio de aprimorar seus conhecimentos técnicos e seu desempenho profissional.

É nesse cenário e com base nos recursos descritos que a Fundap/Egap proporciona, por meio desse suporte, uma capacitação continuada e permanente, que valoriza o servidor e elimina a cultura da escolarização formal clássica, como passaporte único, para a sua capacitação. Esse suporte possibilita a valorização de sua autoestima, melhoria do serviço e melhores oportunidades no mercado de trabalho.

A aprendizagem contínua e permanente fornece aos participantes os instrumentos

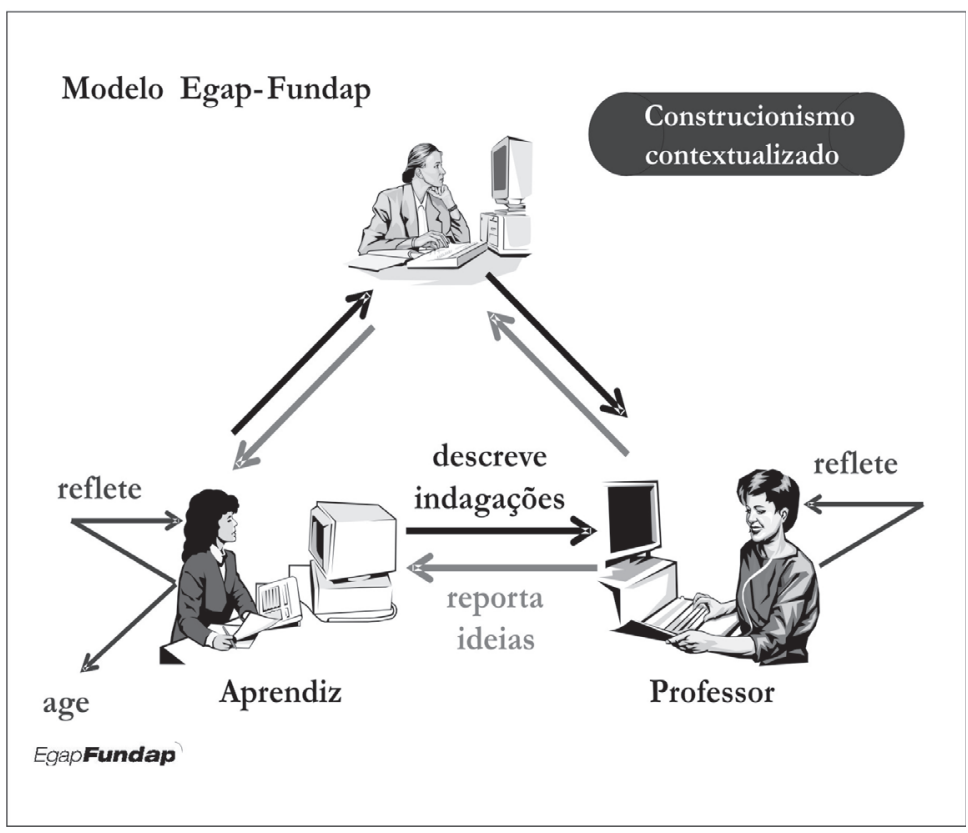

Fonte: Fundap/Egap (São Paulo, Brasil)

Figura 8: Abordagem de EaD que implementa o modelo do construcionismo contextualizado 
essenciais de que necessitam para participar ativamente da sociedade globalizada, uma vez que sabemos que a capacitação do indivíduo não pode ser pensada como algo que acontece entre os muros de uma escola.

Todavia, os ambientes que oferecem uma aprendizagem continuada de qualidade devem atentar para vários aspectos determinantes, entre eles:

- que o participante tenha predisposição para aprender;

- que o ambiente de aprendizagem seja adequadamente organizado e exista interveniente, agente de aprendizagem, que possa ajudar os participantes no processo de aprender;

- que o indivíduo, ao aprender, utilize a sua experiência de vida e os seus conhecimentos adquiridos e, com isso, dê novos significados à atribuição da informação adquirida e, consequentemente, converta essa informação em conhecimento ${ }^{18}$;

- que a ênfase seja "não" na transmissão da informação, mas na discussão em grupo, no compartilhamento da informação, no cultivo da heterogeneidade de ideias e experiências; especificamente, nesse curso, testes e provas são abolidos e a certificação é opcional ${ }^{19}$ e de participação ${ }^{20}$; ou seja, nesse curso não é feita a avaliação da aprendizagem, pois sabemos que os métodos tradicionais de avaliação (testes e provas, por exemplo) não são, muitas vezes, métodos eficientes para avaliar a aprendizagem (entretanto, caso o cliente-demandante do curso - solicite critérios de certificação tradicionais, como provas, a Fundap/Egap atenderá a essa demanda);

- que os mediadores, agentes de aprendizagem, sejam desafiadores, e não só transmissores da informação, e contribuam para o desenvolvimento cognitivo, afetivo e social dos participantes;
- que o ato de aprender seja controlado pelo participante que quer conhecer mais e é motivado pelo prazer de satisfazer suas necessidades e interesses;

- que o incentivo à colaboração leve à satisfação de ser útil, de poder ajudar os colegas, de poder resolver problemas e, muitas vezes, de realizar tarefas sofisticadas; isso gera o sentimento de empowerment (sensação de que podem desenvolver algo considerado quase impossível e, o mais importante, de compreenderem como foi realizado). Esse tipo de sensação não é encontrado nos ambientes educativos tradicionais.

Considerando, como explicitado acima, que os métodos tradicionais de avaliação não são, muitas vezes, métodos eficientes para avaliar a aprendizagem, entendemos que a avaliação da aprendizagem é:

1) Ter um olhar na dimensão interacionista e social ${ }^{1}$.

2) Respeitar os diversos estilos de aprendizagens e as diferenças individuais (CAvellucci, s.d.).

3) Entender que não consiste em reproduções da realidade e, sim, uma interpretação do mundo própria de cada indivíduo, da estrutura do organismo, da sua constituição física, das percepções sensoriais, da forma como experimenta e delineia os objetos (Moraes, 2004).

4) Refletir e aprender a respeitar o "silêncio virtual" no contexto do grupo de discussão via rede. Para Gonçalves (2003), é necessário que se tenha abertura, mais receptividade nesses momentos. Ignorar o silêncio diante do que não está sendo comunicado pode ser uma postura sábia, produtiva, diante do silêncio, ou uma postura esterilizante, que exige resposta rápida e que pode ser reflexo da ansiedade do professor/tutor/moderador. 
5) Perceber a importância do erro nos processos de ensino-aprendizagem. De acordo com Moraes (2004), o erro é um estágio do processo de construção do conhecimento, uma vez que repensar o erro é investigar sua correção; o indivíduo retroage e realimenta o seu processo de construção e corrige os desvios.

6) Entender que o ato de aprender não ocorre em função dos estímulos externos por uma cadeia linear - causa-efeito. Conforme ressalta Moraes (2004), a aprendizagem é um processo circular interativo e recorrente, que ocorre dentro de uma rede neuronal estruturalmente aberta, mas organizacionalmente fechada e que provoca mudanças de condutas, de acordo com a história de interações recorrentes entre o sistema vivo e o meio.

7) Compreender que não existe uma correspondência direta entre uma boa discência e um bom resultado docente (Moraes, 2004).

8) Respeitar a diversidade que favorece a flexibilidade. A diversidade de um sistema de avaliação está mais de acordo com o contexto, métodos e tratamentos curriculares variados e flexíveis (MorAEs, 2004).

9) Adotar um processo de auto-organização ${ }^{22}$, que implica mudança de conduta, é processual, contínuo no tempo e que valoriza a etapa intermediária. Segundo Moraes (2004), o aluno, ao se autoavaliar, estará automaticamente em um processo de autoformação, de desenvolvimento e de aprendizagem. Nesse caso, a avaliação é um instrumento importante para o desenvolvimento da autoestima e conquista da autonomia. Ressalta ainda Moraes (2004) que as situações imprevistas e os objetivos não planejados são elementos importantes para o conjunto de uma boa avaliação e para futuros ajustes desse processo.
10) Priorizar um processo de incentivo e motivação, e de acompanhamento do aprendiz em todo o seu processo de aprendizagem. Segundo Masetto (2003), vivenciamos práticas de avaliação da aprendizagem como identificadoras de resultados obtidos e não como incentivo à aprendizagem. Além disso, essa avaliação não poderá vir ao final de determinada etapa e apenas representada por uma nota. Representa um feedback contínuo e recursivo entre formador e aluno (MAsetTo, 2003).

\section{Conclusões}

Com a criação de uma CVA, é oferecida a possibilidade de se organizar um espaço de colaboração, para discutir os conteúdos do curso e resolver problemas do dia a dia de trabalho dos servidores. Com isso, tal facilidade explora os potenciais da Internet com vistas a poder criar espaço e condições para que se estabeleçam redes de aprendizagem colaborativa, nas quais é possível trocar informações e experiências, e partilhar ideias ou tarefas entre servidores que trabalham em atividades assemelhadas. A intenção é permitir que os servidores adotem novas posturas ou práticas que promovam a tomada de consciência e, então, mudem o modo de compreender o que fazem e, até mesmo, como aprendem.

Embora os cursos possam, na abordagem broadcast, atingir grande número de participantes, eles não têm mecanismos que garantam o máximo rendimento da formação obtida, isto é, indivíduos com autonomia intelectual, pensamento crítico, capacidade de equacionar e resolver problemas, disposição para oferecer sugestões e opiniões, iniciativa e capacidade de organizar-se para cumprir as tarefas no 
tempo e nas condições necessárias para o melhor aprendizado.

Para que essas habilidades e competências sejam adquiridas, é necessário incrementar as atividades previstas na abordagem broadcast com outras atividades, como a CVA. A comunidade passa a ser o espaço para a interação do grupo, local onde são trocadas informações e encaminhadas dúvidas do dia a dia de trabalho.

A comunidade, porém, não se forma ou se mantém de modo espontâneo. Ela necessita ser cultivada e incentivada, por intermédio de mediadores que atuam e se dedicam fundamentalmente a solidificar a participação de todos os envolvidos no curso. Em geral, as estratégias adotadas pelos mediadores, para desencadear a integração e estabelecer a familiaridade com os recursos técnicos, têm resultados satisfatórios nas primeiras semanas e ao longo do curso, com tendência de fortalecimento das relações interpessoais num clima solidário, cordial, de aceitação e, por fim, de segurança.

Contudo, para que esse espaço possa sobreviver, é indispensável a figura do formador, não como único responsável pelo processo de ensino e aprendizagem, mas como indivíduo que assume uma posição de igualdade ao lado dos demais participantes do ambiente e entende que todos - participantes e formadores - detêm conhecimentos específicos, diferenciados e relevantes. Ele é diferenciado por ser a pessoa que tem uma intencionalidade pedagógica e que deve preservar os objetivos originais do curso - o barco tem um timoneiro!

A partir do momento em que se estabelece a confiança e a comunidade começa a ser fortalecida, é possível identificar alunos (participantes) que são verdadeiros especialistas (talentos) e que passam a assumir a responsabilidade de interagir e ajudar os colegas. Com efeito, participantes e formadores passam a ser coautores e coprodutores do seu próprio conhecimento e, também, ambos são coautores e coprodutores do que está sendo produzido e incorporado ao ambiente, em um movimento contínuo e recursivo.

As intervenções dos mediadores têm a função de facilitar o processo de ensino e aprendizagem, incentivar a interação nos fóruns de discussão e auxiliar o participante a descobrir seu potencial intelectual. Estabelecem relações entre as várias áreas de conhecimento, conexões relevantes entre os participantes e os mediadores. Além disso, as intervenções dos mediadores têm o papel de resgatar a funcionalidade $\mathrm{da}$ emoção como condição capaz de proporcionar circunstâncias adequadas aos anseios e desejos dos participantes, tornando esse ambiente adaptável ao aluno e possibilitando uma boa interface de comunicação e interação; porém, sem nunca perder o foco do curso, o controle, o gerenciamento e a animação geral da comunidade.

Na comunidade, o participante (aluno) tem que modificar a sua atitude para vir a ser um agente de busca e construção do conhecimento, tornando-se corresponsável, coautor do seu aprendizado pessoal e profissional. Cada participante é responsável pela construção do conhecimento, de forma autônoma e de acordo com sua disponibilidade e ritmo pessoal. Nesse contexto, o participante pode colocar tanto suas dúvidas quanto os conhecimentos de que dispõe e, portanto, pode ser ao mesmo tempo aprendiz e auxiliar do processo de aprendizagem do colega.

A criação da CVA, associada a um curso que utilize a abordagem broadcast, propicia um ambiente de aprendizagem 
rico e permite que se entendam os diferentes papéis que mediadores e participantes passam a desempenhar. Ademais, faz com que se possam identificar, entre os participantes, talentos que passam a ter papel fundamental na manutenção da comunidade virtual, e não só nela, mas na própria estrutura do governo, que, por intermédio dessa ação de formação, conseguiu identificar diversos servidores com alto grau de especialidade (expertise).

Essa experiência mostra que o conhecimento que o governo quer incrementar encontra-se, de algum modo, imerso em sua própria estrutura. Os especialistas existem, porém estão incógnitos e, possivelmente, ignorados. A criação da CVA pode ser a grande oportunidade de o governo resgatar o potencial intelectual e humano de seus servidores, valorizando a capacidade de pensar, de criar e de se relacionar que eles detêm.

Por fim, percebemos que a economia globalizada expõe a sociedade e as empresas a uma competição acirrada e, nesse contexto, um dos elementos estratégicos dos setores público e privado estará no domínio de saber trabalhar em comunidades virtuais, como uma alternativa de aproveitar e aglutinar o aprendizado dos envolvidos. As interações sociais virtuais (CVA) têm o poder de construir, por meio do compartilhamento das informações e das experiências de seus membros, soluções inovadoras para a sociedade como um todo.

(Artigo recebido em: maio de 2013. Versão final em: junho de 2013.)

\section{Notas}

${ }^{1}$ Piaget (1980) defende que a inteligência possui dois aspectos: o cognitivo e o afetivo. Esse autor considera improvável encontrar o comportamento oriundo da afetividade sem nenhum aspecto cognitivo. Porém, os fatores afetivos e cognitivos são indissociáveis no comportamento. Para o aprendiz desenvolver o conhecimento, é necessário haver interesses intrínsecos. Quando o indivíduo inicia o processo de construção de conhecimento, ele experimenta estados de prazer, ansiedade, fadiga, esforço, aborrecimentos, desapontamento etc. Assim, para Piaget (1980), os aspectos afetivos têm influência no desenvolvimento intelectual de uma pessoa.

${ }^{2}$ Essa solução - comunidade virtual de aprendizagem como apoio a uma capacitação - foi vencedora do Prêmio Mario Covas - 2008: “Comunidade Virtual de Aprendizagem Saúde: criando uma rede 'viva' de colaboradores na área da saúde". Categoria: Inovação em Gestão Pública. Para detalhes a respeito, consulte Prêmio Mario Covas em http://www.premiomariocovas.sp.gov.br/ 2012/index.html.

${ }^{3} \mathrm{Na}$ abordagem broadcast, os meios tecnológicos são utilizados para apenas transmitir informação aos aprendizes. O conteúdo do curso foi preparado e organizado previamente, para só depois de pronto ser oferecido ao participante, que não pode fazer nenhuma alteração. Entretanto, o Curso de Licitação Sustentável (oferecido em 2012), na abordagem broadcast, apresenta um diferencial que é a comunidade virtual de aprendizagem, um espaço que permite a interação entre participantes e formadores. Assim, caso o participante sinta necessidade de interferir no conteúdo do curso, ele deve discutir na comunidade (com os mediadores e colegas) e, se houver pertinência, o conteúdo será alterado pela coordenação do curso, uma vez que o conteúdo do curso estará sempre em construção! 
${ }^{4} \mathrm{O}$ conteúdo do curso é organizado em uma sequência de módulos, planejada por critérios pedagógicos; cada módulo está organizado nos seguintes subcampos: conteúdo; tema; exercícios; apontamentos; atividades complementares; pesquisa; e saiba mais (campos estáticos). O curso oferece também espaços de apoio, como comunidade, fale conosco, glossário, midiateca, questões interessantes, ajuda e créditos.

${ }^{5}$ No tutorial, o conteúdo do curso é apresentado por módulos sequenciais.

${ }^{6}$ A pop-up é uma janela extra que se abre no navegador ao visitar uma página web ou ao acessar uma hiperligação específica.

${ }^{7}$ Módulo 1: Contratações ambientalmente sustentáveis; Módulo 2: Aspectos jurídicos; Módulo 3: Prestação de serviços terceirizados; Módulo 4: Aquisição de materiais; Módulo 5: Obras e serviços de engenharia; Módulo 6: Responsabilidade social; e Módulo 7: Meio ambiente, sociedade e sustentabilidade.

${ }^{8}$ Veja a descrição desses recursos na seção "O primeiro suporte da CVA" deste artigo.

${ }^{9}$ O conteúdo do curso é organizado em uma sequência de módulos, planejada por critérios pedagógicos (bom exemplo é a comparação com uma "casca de cebola"); cada módulo compõese de subcampos: conteúdo; tema; exercícios; apontamentos; atividades complementares; pesquisa; e saiba mais. O curso oferece também espaços de apoio, como comunidade, fale conosco, glossário, midiateca, questões interessantes, ajuda e créditos.

${ }^{10} \mathrm{O}$ aluno é chamado de participante nos ambientes de aprendizagem a distância da Fundap/ Egap.

${ }^{11} \mathrm{O}$ construcionismo contextualizado significa que a construção do conhecimento baseia-se na realização concreta de uma ação que produz um resultado palpável (um artigo, um projeto, um objeto) de interesse pessoal de quem produz. É contextualizado porque o produto (a construção) está vinculado à realidade da pessoa ou do local onde vai ser produzido e utilizado (VALENTE, 1999).

${ }^{12}$ Essa abordagem oferece condições para implantar situações muito favoráveis para a construção do conhecimento e exige do participante envolvimento, acompanhamento e assessoramento constantes. Com base em situações práticas e concretas, mediadores e participantes podem iniciar, conjuntamente, a interaprendizagem e, por intermédio dessas relações intersubjetivas, produzir uma forma autêntica de reflexão e ação. Assim, nesse ciclo de pensar-agir e agir-pensar, toda a comunidade pode, afinal, começar a refletir sobre seu fazer diário.

${ }^{13}$ Endereço do curso: http://www.governoemrede.sp.gov.br/ead/lictsustentavelbr/index.htm

${ }^{14}$ Note que, na estrutura de navegação dos módulos, a apostila (saiba mais) é o último item, ao contrário, repita-se, da maioria dos cursos tradicionais.

${ }^{15}$ Os mediadores técnicos são geralmente os autores do conteúdo programático do curso e também têm o encargo de mediar a comunidade durante três horas diárias. Nas CVA da Fundap/ Egap, o aluno recebe um retorno (feedback) em até 24 horas.

${ }^{16}$ Assim, o estar junto virtual é uma abordagem que favorece a aprendizagem, fundamental para a criação de comunidades virtuais de aprendizagem, e estimula a atuação do aprendiz como coautor desse processo de construção.

${ }^{17} \mathrm{O}$ construcionismo contextualizado significa que a construção do conhecimento baseia-se na realização concreta de uma ação que produz um resultado palpável (um artigo, um projeto, um objeto) de interesse pessoal de quem produz. É contextualizado porque o produto (a construção) está vinculado à realidade da pessoa ou do local onde vai ser produzido e utilizado (VALENTE, 1999).

${ }^{18}$ Para Valente (2009, p. 1), “o conhecimento construído é o produto do processamento, da interpretação, da compreensão da informação. É o significado que atribuímos e representamos 
em nossa mente sobre a nossa realidade. É algo construído por cada um, muito próprio e impossível de ser passado - passamos informação que advém desse conhecimento, porém nunca o conhecimento em si”.

${ }^{19}$ Para o adulto, a vontade de aprender não pode ser explicada somente por mudança de conduta em decorrência de um estímulo externo. Para aprender, o adulto interpreta a realidade de acordo com a sua história e, a partir dessa interpretação, passa a internalizar algo (o produto da significação); são os fatores de ordem interna que criam circunstâncias para ele se motivar a aprender (autorrealização, autoestima, qualidade de vida etc.).

${ }^{20}$ A certificação do Curso de Licitação Sustentável Brasil é de participação e opcional. O participante que desejar certificar-se deverá realizar todos os módulos do curso e participar ativamente da comunidade virtual de aprendizagem, com o envio de mensagens significativas de conteúdo técnico (conteúdo do curso), no período de dois meses de vigência de sua turma. Mensagens postadas nos fóruns "Café" e "Bem-vindo! Apresente-se e Colabore" não são consideradas para essa avaliação.

${ }^{21}$ No que se refere à dimensão interacionista, as relações que possibilitam trocas intelectuais são, segundo Moraes (2004), inexoráveis ao desenvolvimento do pensamento do sujeito. Para essa autora, o conhecimento em sua essência é dialético, uma vez que toda interação implica dialogicidade e produção compartilhada. No que concerne à dimensão social, ainda conforme Moraes (2004), o indivíduo, no ato de conhecer, realiza algo, experimenta e reconstrói a sua própria realidade e muda interiormente, por meio dessa relação consigo mesmo e ante a relação com os seus pares. Para essa autora, a aprendizagem é um "processo de auto-organização e de reorganização mental e emocional".

${ }^{22}$ Os processos auto-organizadores do indivíduo acentuam a dimensão auto-organizadora da avaliação. Isso nos acena que a avaliação deve proporcionar informações imprescindíveis para a formação do aprendiz e não apenas oferecer informações sobre certo aluno em momentos determinados pelo formador. A avaliação, a partir dessas teorias, passa a ser também uma parte importante do processo de auto-organização, tanto no nível do indivíduo quanto da organização. E os processos auto-organizadores acentuam, com base nesses enfoques, a dimensão autoformadora da avaliação. Isso indica que ele deve oferecer informações importantes para o processo de autoformação do aluno, colaborando para o seu próprio processo de desenvolvimento e aprendizagem. Desse ponto de vista, a avaliação é um instrumento importante para a autonomia do aluno (Moraes, 2004).

\section{Referências bibliográficas}

Castells, M. The rise of the network society. Oxford: Blackwell Publisher, 1996.

Cavellucci, L. C. B. Estilos de aprendizagens: um olhar nas diferenças de aprendizagens. São Paulo: Unicamp, s. d., mimeo.

DiAs, Paulo. Mediação colaborativa das aprendizagens nas comunidades virtuais e de prática. In: Costa, F. A.; Peralta, H.; Viseu, S. (Orgs.) As TIC na educação em Portugal. Porto: Porto Editora, 2007. 
FARIA, R. M. B. Formação de pessoal para o setor público: a experiência da Fundap. In: Cadernos Fundap, 21. São Paulo: Fundap, 1997, pp. 189-197.

GonçALVES, M. I. R. Reflexões sobre silêncio virtual no contexto do grupo de discussão na aprendizagem via rede. In: Revista Pateo: Multidisciplinaridade. [s. 1.], ano 7, n. 26, maio/ jul., 2003.

LÉvy, Pierre. Cibercultura. Rio de Janeiro: Editora 34, 2000.

LiTwIN, Edith (Org.). Educação a distância: temas para o debate de uma nova agenda educativa. Porto Alegre: Artmed, 2001.

Masetтo, M. T. Competência pedagógica do professor universitário. São Paulo: Summus, 2003.

Moraes, M. C. Pensamento eco-sistêmico: educação, aprendizagem e cidadania no século XXI. Petropólis/RJ: Vozes, 2004.

Moran, J. M. Ensino e aprendizagem inovadores com tecnologias audiovisuais e telemáticas. In: Moran, J. M.; Masetto, M. T.; Behrens, M. A. (Orgs.) Novas tecnologias e mediação pedagógica. Campinas: Papirus, 2000.

Palloff, R. M.; Pratt, K. Construindo comunidades de aprendizagens no ciberespaço. Porto Alegre: Artmed, 2002.

Piaget, J. Seis estudos de psicologia. Rio de Janeiro: Forense-Universitária, 1980.

Rocha, H. V. O ambiente TelEduc para educação a distância baseada na Web: princípios, funcionalidades e perspectivas de desenvolvimento. In: Moraes, C. M. (Org.) Educação a distância: fundamentos e práticas. Campinas: Unicamp/Nied, 2002, p. 197-212. [Online] Disponível em: http://www.nied.unicamp.br/oea/pub.html.

SILva, Bento. Educação e comunicação. Braga: CEEP/Universidade do Minho, 1998.

Tavares-Silva, Tania. Mediação pedagógica, nos ambientes telemáticos, como recurso de expressão das relações interpessoais e da construção do conhecimento. 2003. Dissertação (Mestradoem Educação: Currículo) - Pontifícia Universidade Católica de São Paulo, São Paulo. - A educação baseada no paradigma da produção em massa, de servidores do Estado de São Paulo, via cursos on-line: a comunidade virtual de aprendizagem como recurso para valorizar e resgastar a capacidade de pensar, interagir e construir do aprendiz. 2006. Tese (Doutorado em Educação: Currículo) - Pontifícia Universidade Católica de São Paulo, São Paulo.

VALENTE, J. A. Formação de professores: diferentes abordagens pedagógicas. In: VALENTE, J. A. (Org.) O computador na sociedade do conhecimento. Campinas: Unicamp/Nied, 1999.

. Diferentes abordagens de educação a distância. In: Multiply. [Online] Acesso em: 10 agosto 2009. Disponível em: http://claudioalex.multiply.com/video/ item/665.

VAlente, J. A.; TAvares-Silva, T. A capacitação de servidores do estado via cursos on-line: adequando soluções às diferentes demandas. In: SILVA, M. (Org.) Educação online: teorias, práticas, legislação e formação corporativa. São Paulo: Edições Loyola, 2003. p. 485-500.

Wenger, E. Communities of practice: learning, meaning and identity. Nova York: Cambridge University Press, 1998. 


\section{Resumo - Resumen - Abstract}

Os suportes de uma comunidade virtual de aprendizagem: uma experiência do Governo do Estado de São Paulo, Brasil

Tania Tavares-Silva, Paulo Dias e José Armando Valente

Este artigo apresenta os quatro suportes de uma comunidade virtual de aprendizagem: a criação de um curso, na abordagem broadcast, contextualizado e significativo; a mediação técnica e pedagógica; participantes responsáveis e envolvidos; e a aprendizagem continuada. Criada pela Fundação do Desenvolvimento Administrativo e Escola de Governo e Administração Pública, instituições vinculadas à Secretaria de Gestão Pública do Estado de São Paulo (Brasil), a comunidade virtual de aprendizagem foi utilizada como recurso para capacitação on-line de servidores públicos. Dessa experiência singular, verificou-se que um dos elementos estratégicos dos setores público e privado está no domínio de saber trabalhar em comunidades, como uma alternativa de aproveitar e aglutinar o aprendizado dos envolvidos. As interações sociais virtuais têm o poder de construir, por meio do compartilhamento das informações e das experiências de seus membros, soluções inovadoras para a sociedade como um todo.

Palavras-chave: aprendizagem continuada; capacitação on-line; comunidade virtual de aprendizagem; interações sociais; suportes de aprendizagem

Los soportes de una Comunidad Virtual de Aprendizaje: una experiencia del Gobierno del Estado de Sao Paulo, Brasil

Tania Tavares-Silva, Paulo Dias y José Armando Valente

En este trabajo se presentan los cuatro soportes de una comunidad virtual de aprendizaje: la creación de un curso, el enfoque de la difusión, contextualizado y significativo; mediación técnica y pedagógica; los participantes responsables e involucrados; y el aprendizaje permanente. Creada por la Fundación de Desarrollo Administrativo y la Escuela de Gobierno y Administración Pública, instituciones vinculadas con el Departamento de Administración Pública del Estado de Sao Paulo (Brasil), una comunidad virtual de aprendizaje fue utilizada como un recurso para la formación en línea de los servidores públicos. Esta experiencia única se constató que uno de los elementos estratégicos de los sectores público y privado está trabajando en el campo del conocimiento en las comunidades, como una alternativa para aprovechar y unir el aprendizaje de los participantes. Las interacciones sociales tienen el poder de crear, a través del intercambio de información y experiencias de sus miembros, las soluciones innovadoras para la sociedad en su conjunto.

Palabras clave: el aprendizaje permanente; la formación en linea; la comunidad virtual de aprendizaje; las interacciones sociales; soportes de aprendizaje

The principles of a virtual learning community: an experience of the Department of Public Administration of the State of São Paulo, Brazil

Tania Tavares-Silva, Paulo Dias and José Armando Valente

This article presents four principles of a virtual learning community: the creation of a contextualized and meaningful course, in a broadcast approach; the technical and pedagogical mediation; responsible and involved participants; and the continuous learning. Created by the Administrative Development Foundation and the Government and Public Administration School, institutions linked to the Department of Public Administration of the State of Sao Paulo, Brazil, the virtual learning community was used as a resource for on-line training of public 
servants. From that singular experience, it was found out that one of the strategic elements of public and private sectors is in the mastery of knowing how to work in communities, as a way to harness and unite the learning of those involved. Social interactions have the power to build, through the sharing of information and experiences of its members, innovative solutions to society as a whole.

Keywords: lifelong learning; on-line training; virtual learning community; social interactions; learning supports

Tania Tavares-Silva

É pós-doutora em Novas Tecnologias pela Universidade do Minho, Portugal. Técnica da Fundação do Desenvolvimento Administrativo (Fundap). Contato: ttavares@fundap.sp.gov.br

Paulo Dias

É doutor em Educação pela Universidade do Minho, Portugal. Reitor da Universidade Aberta, Portugal. Contato: paulo.dias@uab.pt

José Armando Valente

É livre docente na área de Tecnologias Educacionais, pela Universidade Estadual de Campinas (Unicamp). Professor e chefe do Departamento de Multimeios, Mídia e Comunicação do Instituto de Artes e pesquisador do Núcleo de Informática Aplicada à Educação (Nied) da Universidade Estadual de Campinas (Unicamp). Contato: jvalente@unicamp.br

Edição e revisão técnica deste artigo

João Vaz

É professor da Escola Diadema de Administração Pública (Edap) e da Uniesp/FaD. Mestre em Semiótica e Linguística Geral pela Faculdade de Filosofia, Letras e Ciências Humanas (FFLCH) da Universidade de São Paulo (USP); e especialista em EaD pelo Senac/RJ. 